\title{
Travel decision reversals paradox of competitive metro lines: The Equate- to-differentiate Theory Interpretation
}

\author{
Nian Zhang ${ }^{1}$, Yiyuan Zhang ${ }^{1}$ and Xia Luo ${ }^{1, a}$ \\ ${ }^{1}$ School of Transportation and Logistics, Southwest Jiaotong University, 999 Xian Road, Chengdu 611756, PRC
}

\begin{abstract}
Based on the equate-to-differentiate theory, this paper studies the paradox of preference reversal and choice reversal in traffic decision-making in parallel sections of Chengdu Metro Line No.2 and No.4. Travel decision reversals: preference reversals phenomenon (PRP) and choice reversals phenomenon (CRP) are found in the travel investigation for Chengdu Metro Line No.2 and No.4, and the reversals cannot be well explained by random error. Through experimental design of cautious control, the existence of these phenomena is confirmed. This paper establishes the judgment dimension system of option attributes, and designs three groups of psychological experiment in certain, uncertain and risk scenarios. Data analysis shows that PRP and CRP can be explained by the equate-todifferentiate interpretation. The phenomena of reversal are not due to the fact that preference and choice really reverses, but the variable strategic process. The equate-to-differentiate interpretation shows good consistency in the experiments and can predict and explain the preference and choice reversal of travel decision. At last, a comparative analysis which compares the results of the two models of the decision field theory is made and finally the conclusion is obtained.
\end{abstract}

\section{Introduction}

Preference reversal is a strange phenomenon of decision behaviours, expressed in the inconformity between the choice and evaluation for the choice game with roughly same expected value, but diverse incomes. Slovic and Lichtenstein (1968) discovered this phenomenon in a risk behaviour research and confirmed its existence through three groups of game experiments (1971) [1]. Preference reversal violated the principle of classical economics theory and decision criterion, thus it was widely oppugned in the economics and psychology fields. For example Greeter and Plott (1979) tried to eliminate preference reversal through the control of economic factors in the experiment [2], and Reilly (1982) tried to improve the communication with subjects, increase their motivation and acquaint them with expected utility theory to eliminate the preference reversal [3]. But the result showed that the preference reversal phenomenon still exists to a considerable extent, which confirmed the universality of its existence. Then the scholars changed to explain the preference reversal. In the field of economics, scholars attributed PRP to the violation of the principles of classical expected utility theory, for example Loomes and Sugden (1982) suggested that PRP violated the principle of transitivity in the regret theory [4]; Holt and Karni(1986) attributed the preference reversal to the violation of the independence principle by analysing the determination of the price pattern (BDM) [5-6]. In recent years, Schmidt and Hey (2004) thought that PRP originated from random error, and an extended error model was proposed to explain PRP [7]. The psychological interpretation of PRP is mainly focused on the development of mental processes. For example, Mellers (1992) proposed the process change theory, which leads to the PRP [8]; Birnbaum (1992) put forward the allocation weight theory by the combination of information decision strategy, and the PRP is well explained, but the model results cannot be predicted [9]. Based on the Equate-to-differentiate approach, Shu Li (2006) explained the PRP [10].

Choice reversals refer to the phenomenon that subsequent choice (preference) changes when decisionmakers repeatedly choose the same question in decisionmaking behaviour. Different from the inconformity between value judgment and choice (preference) in preference reversal, the phenomenon of choice reversal is the inconformity between the previous decision result and the later one, when the decision-maker is facing the essentially same choices [11]. In the field of choice reversals, scholars used the stochastic model to explain the phenomenon of choice reversals and believed that the choice behaviour had random features. For example, Aschenbrenner (1984) proposed that in the either-or problem of multi-dimension options, decision-making is cumulatively formed by the value differences of the different dimension options. Busemeyer (1993) proposed that the individual's preference for choice branches is a probability function of an interval of $[0,1]$. The formation of choice is the cumulative result of time diffusion [12].

\footnotetext{
${ }^{\text {a }}$ Corresponding author: xia.luo@263.cn
} 
The research on choice reversals in recent years mainly includes that Shu Li (2005-2009) studied the choice reversals of the either-or problem in repetitive experiments under three different scenarios based on the equate-to-differentiate interpretation [13]. It is verified that the equate-to-differentiate interpretation can explain the phenomenon of choice reversals well, and in the framework of equate-to-differentiate theory, the violation of decision axioms in different domain decision problems is also explained. At the same time, in the face of multiple choices, choice reversals were later developed as a study of the inverse problem which is particularly evident in the analytic hierarchy process (3). Shu Li (2015) constructed the "three-member cycle" choice experiment and studied the issue of choice reversals again, further explaining the inconformity nature of the choice [14]. Recent years, Nian Zhang (2018) preliminarily study on preference reversal in traffic under the equateto-differentiate theory [15].

The economic models and psychological models about PRP and CRP have not yet been widely supported by experiments, and the explanation has not been uniformly agreed. At present, there is less research on the preference and choice reversals of traffic behaviour, but the phenomenon of reversals is not uncommon. This paper is trying to demonstrate the existence of preference and choice reversals phenomenon in the travel decision through "cautious control" and explain the travel decision reversals designs psychological experiment under the equate-to-differentiate theory.

\section{PRP and CRP}

In our research, the violation phenomenon of preference reversal and choice reversal is first found in the bus lines between the two campuses of Southwest Jiaotong University, and the applicability of equate-to-differentiate theory has been demonstrated partially and preliminarily. This paradox is more prominent in the two choice branches whose expectations are close to each other. In order to validate the universality of the reversals and prove the practicability of equate-to-differentiate theory, the study is extended to the Chengdu Metro Line No.2 and Metro Line No.4 which are almost parallel between Chengdu Sport Institute and Sichuan Provincial Hospital of TCM. As shown in Figure 1.

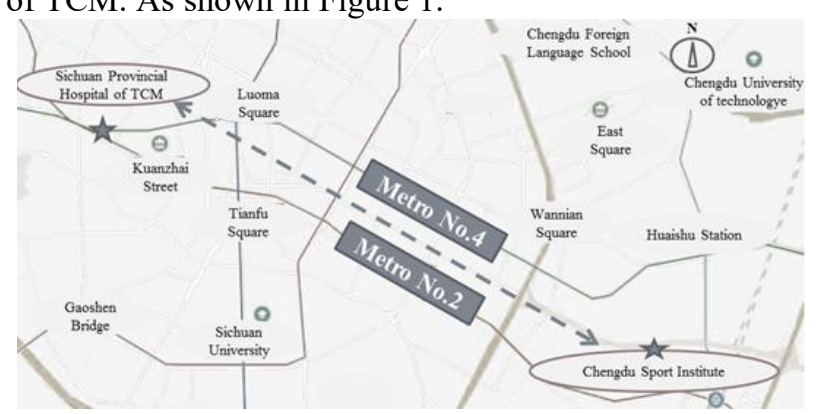

Figure 1. Metro lines

Travelers are asked to evaluate the both metro lines, choose the one they preferred, and the same choice task is taken for the second time 7 days later. The guidance is "Assume that at six o'clock this afternoon you will travel from Chengdu Sport Institute to Sichuan Provincial Hospital of TCM. Metro Line No.2 and Metro Line No.4 are provided, please score the two modes of traffic respectively and choose the one that you preferred according to the attribute information blow" and the result is shown in Table 1-2.

Table 1. Result of preference investigation

\begin{tabular}{|c|c|c|c|c|}
\hline & \multicolumn{2}{|c|}{ Evaluation } & \multirow[b]{2}{*}{ Total } \\
\hline & & $\begin{array}{c}\text { Better } \\
\text { evaluation for } \\
\text { Metro Line } \\
\text { No. } 2\end{array}$ & $\begin{array}{c}\text { Better } \\
\text { evaluation } \\
\text { for Metro } \\
\text { Line No.4 }\end{array}$ & \\
\hline \multirow{2}{*}{ Preference } & $\begin{array}{c}\text { Metro } \\
\text { Line } \\
\text { No. } 2\end{array}$ & 29 & 17 & 46 \\
\hline & $\begin{array}{c}\text { Metro } \\
\text { Line } \\
\text { No. } 4\end{array}$ & 11 & 13 & 24 \\
\hline \multicolumn{2}{|c|}{ Total } & 40 & 30 & 70 \\
\hline
\end{tabular}

Table 2. Result of repeated choice

\begin{tabular}{|c|c|c|}
\hline & The first round & The second round \\
\hline Metro Line No.2 & 43 & 49 \\
\hline Metro Line No.4 & 27 & 21 \\
\hline
\end{tabular}

In the investigation, travellers' preferences and evaluations for the metro lines is inconsistent, 46 travellers choose the Metro Line No.2, while in the evaluation, only 40 travellers rated the Metro Line No.2 better. In choice option, 43 travellers choose Metro Line No. 2 and the second increased to 49 in the second time.

\section{Equate-to-differentiate theory}

As a non-compensatory model, the equate-to-differentiate theory is widely used to explain the framework effect problem and follows the principle of detective dominance, of which the core concept is "Equating to differentiate makes decision, avoiding the complexity does a simple judgment". According to the equate-to-differentiate theory, the travel mode choice model constructed in this paper is based on the following two principles [15].

The choice of transportation mode is not determined by some expected maximum value of the alternative modes, and the traveler is not able to integrate the attributes of the modes of transportation. The difference in one attribute of transportation mode cannot be compensated for by the other attributes.

Travel decision-making allows for variability in selection when repeating choices, and it is not a random model in nature, but a "individual" determinant model. The effect of travelers' instant experience to transportation modes differs due to the different scenes, and the choice of traveler is determined according to the unifying and discrimination of the attribute dimensions of the traffic modes.

The key problem of preference reversal is that if the choice is determined by some desired maximum value. The theory of the Equate-to-differentiate Interpretation does not think that traveller can achieve multidimensional integration, and disadvantages of transportation in one dimension cannot be compensated 
by advantage of another dimension, in face of multidimensional choice, and the decision is more inclined to adopt the non-compensatory decision rules. Meanwhile, the key problem of choice reversal is that if the choice can be obedient to the principle of randomness. Also, the variability of choice decision is allowed in Equate-to-differentiate theory, however, the model is not a probability model essentially, but a decisive model of "individual". The instant experience utility is based on the attribute dimension of different trip scenarios. According to Shu Li's axiomatic analysis of the theory, it is assumed that $A=\left(A_{1}, A_{2}, \ldots, A_{n}\right)$ is a limited set of travel options. $A_{1}, A_{2} \in A$ is the two modes of transportation that can be selected and the symbol " $>$ " indicates preference; $B=\left(B_{1}, B_{2}, \ldots, B_{m}\right)$ is a subjective space that characterizes the $m$ dimensional attributes of set $A$ and each dimension of option $A_{i}$ can be any metric level variables (like nominal variable, sequence variable, isometric variable and ratio variable), where $A_{i}$ can only be represented by the point $i$ of the dimensional space; $C=\left(C_{1}, C_{2}, \ldots, C_{m}\right)$ is a set of evaluation for travel modes. The Equate-to-differentiate Interpretation can be described as follows (20).

$$
E\left(A_{1}, A_{2}\right)_{j}=\left\{\begin{array}{l}
\left(a_{1}, a_{2}, \ldots, a_{m}\right)^{T}, \text { when } U_{j_{0}}^{t, p}\left(O_{1, j}\right)-U_{j_{0}}^{t, p}\left(O_{2, j}\right)>0 \\
\left(b_{1}, b_{2}, \ldots, b_{m}\right)^{T}, \text { when } U_{j_{0}}^{t, p}\left(O_{1, j}\right)-U_{j_{0}}^{t, p}\left(O_{2, j}\right)<0
\end{array}\right\}
$$

In the formula: $O_{i j}(j=1, \ldots, m)$ is the objective value level of option $A_{i}$ in dimension $j ; U_{i j}=U_{j}^{t, p}\left(O_{i, j}\right)$ is a monotonic utility function of the subjective value level of $A_{i}$ in dimension $j$, and $p$ is the function of the individual formed at a certain time interval $t$.

$$
\begin{gathered}
a_{j}=\max \left\{0, U_{j_{0}}^{t, p}\left(O_{1, j}\right)-U_{j_{0}}^{t, p}\left(O_{2, j}\right)\right\} \\
b_{j}=\min \left\{0, U_{j_{0}}^{t, p}\left(O_{1, j}\right)-U_{j_{0}}^{t, p}\left(O_{2, j}\right)\right\} \\
j_{0}=\arg \max \left\{\left|U_{j_{0}}^{t, p}\left(O_{1, j}\right)-U_{j_{0}}^{t, p}\left(O_{2, j}\right)\right|, j=1, \ldots, m\right\}
\end{gathered}
$$

In the formula: $a_{j}, b_{j}$ represent the difference of the option dimensions; $j_{0}$ represents the dimension with the greatest difference in subjective utility.

According to the Equate-to-differentiate Interpretation, people can form a preference only if the difference of option dimensions conforms to the principle of dominance, that is

$$
\left\{\begin{array}{l}
A_{1}>A_{2}, E\left(A_{1}, A_{2}\right) \geq 0 \operatorname{and} E\left(A_{1}, A_{2}\right) \neq 0 \\
A_{1}<A_{2}, E\left(A_{1}, A_{2}\right) \leq 0 \operatorname{and} E\left(A_{1}, A_{2}\right) \neq 0
\end{array}\right.
$$

In order to explore whether preference and choice reversal of travel mode is a random process or an equateto-differentiate process, we redesign three groups of experiment and analyse the results.

\section{Random error interpretation}

For this kind of scenario, the result is usually considered as invalid data generated by random errors, but the inconformity ratio in the statistical results is almost close to $10 \%$, the questionnaire design is questioned. Therefore, we try to reduce the errors frequency through the "cautious control" of the investigation. The specific measures are as follows and the problem is set in Table 3 .

- Increase the attribute description of the choice branch and strengthen the communication with the subjects(3).

- Expand the survey sample to 294 teachers and students who have travelled at least twice in the past month, and use inter-group design, randomly divide them into three groups.

- In order to avoid subjects from rushing to give extreme results as 0 points or 1 point, the evaluation is based on "very bad, bad, moderate, good, very good" and

\begin{tabular}{|c|c|c|c|}
\hline \multicolumn{4}{|c|}{$\begin{array}{l}\text { Guidance: Assume that at six o'clock this afternoon you will } \\
\text { travel from Chengdu Sport Institute to Sichuan Provincial } \\
\text { Hospital of TCM. Metro Line No.2 and Metro Line No.4 are } \\
\text { provided, please score the two modes of traffic respectively } \\
\text { and choose the one that you preferred according to the } \\
\text { attribute information blow. }\end{array}$} \\
\hline & $\begin{array}{l}\text { Ride time } \\
\text { (min) }\end{array}$ & $\begin{array}{l}\text { Walking time } \\
\text { (min) }\end{array}$ & Load factor \\
\hline $\begin{array}{c}\text { Metro } \\
\text { Line No.2 }\end{array}$ & 50 & 10 & $60 \%$ \\
\hline $\begin{array}{c}\text { Metro } \\
\text { Line No.4 }\end{array}$ & 40 & 15 & $80 \%$ \\
\hline \multicolumn{4}{|c|}{$\begin{array}{l}\text { Through the "cautious control", the invalid } \\
\text { questionnaire is basically eliminated, but the } \\
\text { inconformity does not disappear, and the proportion still } \\
\text { reaches to } 6 \% \text {. The result is shown in Table } 4-5 \text { (The } \\
\text { same score is not considered). }\end{array}$} \\
\hline
\end{tabular}
the preference is graded according to "must not choose, will not choose, does not matter, will choose, and must

\begin{tabular}{|c|c|c|c|c|}
\hline & \multicolumn{2}{|c|}{ Evaluation for better } & \multirow[b]{2}{*}{ Total } \\
\hline & & $\begin{array}{l}\text { Metro Line } \\
\text { No. } 2\end{array}$ & $\begin{array}{l}\text { Metro Line } \\
\text { No.4 }\end{array}$ & \\
\hline \multirow{2}{*}{ Preference } & $\begin{array}{l}\text { Metro Line } \\
\text { No. } 2\end{array}$ & 122 & 66 & 188 \\
\hline & $\begin{array}{l}\text { Metro Line } \\
\text { No.4 }\end{array}$ & 50 & 56 & 106 \\
\hline \multicolumn{2}{|c|}{ Total } & 172 & 122 & 294 \\
\hline
\end{tabular}
choose".

Table 3. Problems setting of the "Cautious Control"

Table 4 Result of preference reversal

The test result $\left(\chi^{2}(1)=8.771, p<0.01\right)$ does not show significant irrelevance between preference and evaluation. According to the decision theory (axiom), traveller should prefer the traffic mode which they evaluate better, but the statistical analysis results show that this is not the case, which leads us to question the relationship between "preference" and "evaluation", and there is also a problem with the idea of judging "preference" by "evaluation".

Meanwhile, travellers' choice is also inconsistent in twice investigation, when the same investigation is taken in the second time, some travellers change their choices, and the choice variation still exists. The statistical test results show that there is no significant correlation ( $p h i=0.78$, sig $=0.42, p<0.05)$ in variation ratio, sample size and interval time. The occurrence of variation 
cannot be reasonably explained through random errors, and the phenomenon of choice reversal does exist

Table 5 Result of choice reversal

\begin{tabular}{|c|c|c|c|c|c|c|}
\hline \multirow[b]{2}{*}{$\begin{array}{c}\text { Choic } \\
\text { e }\end{array}$} & \multicolumn{2}{|c|}{$\begin{array}{c}\text { Group one } \\
(\mathrm{N}=46,7 \text { days } \\
\text { interval })\end{array}$} & \multicolumn{2}{|c|}{$\begin{array}{c}\text { Group two } \\
(\mathrm{N}=99,10 \text { days } \\
\text { interval })\end{array}$} & \multicolumn{2}{|c|}{$\begin{array}{c}\text { Group three } \\
(\mathrm{N}=149,21 \\
\text { days interval })\end{array}$} \\
\hline & $\begin{array}{l}\text { The } \\
\text { first } \\
\text { invest } \\
\text { igatio } \\
\mathrm{n}\end{array}$ & $\begin{array}{c}\text { The } \\
\text { secon } \\
d \\
\text { invest } \\
\text { igatio } \\
n\end{array}$ & $\begin{array}{l}\text { The } \\
\text { first } \\
\text { invest } \\
\text { igatio } \\
n\end{array}$ & $\begin{array}{c}\text { The } \\
\text { secon } \\
d \\
\text { invest } \\
\text { igatio } \\
n\end{array}$ & $\begin{array}{c}\text { The } \\
\text { first } \\
\text { invest } \\
\text { igatio } \\
\mathrm{n}\end{array}$ & $\begin{array}{c}\text { The } \\
\text { secon } \\
\mathrm{d} \\
\text { invest } \\
\text { igatio } \\
\mathrm{n}\end{array}$ \\
\hline $\begin{array}{c}\text { Metro } \\
\text { Line } \\
\text { No. } 2\end{array}$ & 24 & 28 & 63 & 70 & 111 & 98 \\
\hline $\begin{array}{c}\text { Metro } \\
\text { Line } \\
\text { No.4 }\end{array}$ & 22 & 18 & 36 & 29 & 38 & 51 \\
\hline $\begin{array}{c}\text { Inconf } \\
\text { ormity } \\
\text { ratio }\end{array}$ & \multicolumn{2}{|c|}{$8.7 \%$} & \multicolumn{2}{|c|}{$7.1 \%$} & \multicolumn{2}{|c|}{$8.7 \%$} \\
\hline
\end{tabular}

\section{Experiment}

In order to explore whether the equate-to-differentiate theory can be used to explain preference reversal of metro travel, we add a psychology matching task experiment that the participants are asked to choose "the option of the greatest difference". Three travel task scenarios under the conditions of certainty, uncertainty and risk are redesigned as follows. In the experiment, $A_{1}$ and $A_{2}$ respectively mean Metro Line No.2 and Metro Line No.4, $B_{1}, B_{2}$ and $B_{3}$ respectively mean the dimension of attributes difference, $C_{1}$ and $C_{2}$ mean the travel mode for better evaluation. Before the experiment, each participant was locked by ID number, aiming to track the change of the participant's choice chain.

\section{Scenario I}

Students and teachers of Chengdu Sport Institute were informed to go to the Sichuan Provincial Hospital of TCM to participate in a free physical examination. Participants are asked to choose the one they preferred based on the travel information provided, and to circle the matching option which is considered to have the greatest difference, as shown in Table 6.

Table 6. Preference and matching task of scenario I

\begin{tabular}{|c|c|c|}
\hline Preference & Attribute 1 & Attribute 2 \\
\hline$A_{1}$ & arrive in 40 minutes & comfortable inside \\
\hline$A_{2}$ & arrive in 30 minutes & crowded inside \\
\hline Matching & \multicolumn{2}{|c|}{ Differences in attribute dimensions } \\
\hline$B_{1}$ & "arrive in 40 minutes" and "arrive in 30 \\
minutes"
\end{tabular}

46 students participate in the experiment, and the choice option was performed again for the second time after 7 days.

\section{Scenario II}

The purpose of setting uncertain scenarios is to reduce the imbalance of dimension difference caused by the "absolutism" attribute in deterministic scenario, and promote the representation of value judgment process. Subjects are informed that a free physical examination will be held after 50 minutes in Sichuan Provincial Hospital of TCM, and the number of participants is limited. Metro Line No.2 and Metro Line No.4 are available to choose, but the load factor is uncertain. In order to explore whether the Equate-to-differentiate model can predict travel choices, we change the sequence of tasks [5]. Participants are asked to perform matching tasks, preference selection, and evaluation tasks in turn. Furthermore, in order to study whether the choice of transportation mode is a multi-dimensional attribute combination process or the equate-to-differentiate process, we add the walking time attribute, to make the overall expected travel time slightly different, as shown in Table 7.

Table 7. Preference and matching task of scenario II

\begin{tabular}{|c|c|c|c|}
\hline Preference & Attribute 1 & Attribute 2 & Attribute 3 \\
\hline$A_{1}$ & $\begin{array}{l}\text { arrive in } 40 \\
\text { minutes }\end{array}$ & comfortable & $\begin{array}{l}11 \text { minutes } \\
\text { on foot }\end{array}$ \\
\hline$A_{2}$ & $\begin{array}{l}\text { arrive in } 30 \\
\text { minutes }\end{array}$ & $\begin{array}{l}\text { probably } \\
\text { crowded }\end{array}$ & $\begin{array}{l}15 \text { minutes } \\
\text { on foot }\end{array}$ \\
\hline Matching & \multicolumn{3}{|c|}{ Differences in attribute dimensions } \\
\hline$B_{1}$ & \multicolumn{3}{|c|}{$\begin{array}{c}\text { "arrive in } 40 \text { minutes" and "arrive in } 30 \\
\text { minutes" }\end{array}$} \\
\hline$B_{2}$ & \multicolumn{3}{|c|}{$\begin{array}{c}\text { "probably comfortable" and "probably } \\
\text { crowded" }\end{array}$} \\
\hline$B_{3}$ & \multicolumn{3}{|c|}{ "11 minutes on foot" and " 15 minutes on foot" } \\
\hline
\end{tabular}

99 travelers participated in the experiment and the same experiment was performed again for the second time after 10 days.

\section{Scenario III}

In uncertain conditions, subjects may not have a clear profitability of travel result, in consideration of the uncertain transit time of the bus, a risk task scenario is designed to explore whether the introduction of precise probability can improve the individual's judgment level to reduce the "error" and whether non-compensation principle can explain the preference and choice reversals[6]. 149 graduate students are randomly selected to take the test and informed that an entrance examination will be held in Sichuan Provincial Hospital of TCM after 50 minutes. Now it is accepting register, and the number of register is limited. Late arrivals will be postponed to the next week and the entry may be affected. Two metro lines are available to choose, subjects are required to complete matching, choice, and evaluation tasks in turn. This scenario is shown in Table 8.

Table 8. Preference and matching task of scenario III

\begin{tabular}{|c|c|c|}
\hline Preference & Attribute 1 & Attribute 2 \\
\hline$A_{1}$ & $\begin{array}{c}\text { 80\% possibility of 8 } \\
\text { minutes in advance }\end{array}$ & $\begin{array}{c}20 \% \text { possibility of } 2 \\
\text { minutes late }\end{array}$ \\
\hline$A_{2}$ & $\begin{array}{c}40 \% \text { possibility of } 10 \\
\text { minutes in advance }\end{array}$ & $\begin{array}{c}10 \% \text { possibility of } 8 \\
\text { minutes late }\end{array}$ \\
\hline Matching & Differences in attribute dimensions \\
\hline$B_{1}$ & $\begin{array}{c}80 \% \text { possibility of 8 minutes" or " } 40 \% \\
\text { possibility of 10 minutes" in advance }\end{array}$ \\
\hline$B_{2}$ & $\begin{array}{c}\text { "20\% possibility of 2 minutes late" or " } 10 \% \\
\text { possibility of 8 minutes late" }\end{array}$ \\
\hline
\end{tabular}


In this risk scenario, the expected time is approximately the same. The best dimension is that the Metro Line No.4 arrives 2 minutes ahead of the Metro Line No.2. Therefore, it can help subjects to submit the resume as early as possible and reserve a certain amount of preparation time. The worst result is that the Metro Line No.2 arrives 6 minutes later than the Metro Line No.4, and it is possible to lose the opportunity for register. 149 subjects in the Chengdu Sport Institute take part in the experiment and the same experiment is performed again for the second time after 15 days.

\section{Results}

In scenario I, Table 9 shows that participants who chose option $A_{l}$ pay more attention to the difference of travel time, and the waiting time is "assimilated", and participants who chose option $A_{2}$ pay more attention to the difference of waiting time, and the travel time is "assimilated". The result of the chi-squared test ( $\left.p h i=-0.51, \chi^{2}(1)=15.79, p<0.01\right)$ shows that the matching result can explain the choice of traffic mode under uncertain conditions, and it supports the rationality of the equate-to-differentiate interpretation model.

Table 9. Preference and matching result in scenario I

\begin{tabular}{|c|c|c|c|c|}
\hline \multirow{2}{*}{$\begin{array}{c}\text { The first } \\
\text { experiment }\end{array}$} & \multicolumn{4}{|c|}{ Matching } \\
\cline { 2 - 5 } & & $B_{1}$ & $B_{2}$ & Total \\
\hline \multirow{2}{*}{ Preference } & $A_{1}$ & 4 & $\underline{24}$ & 28 \\
\cline { 2 - 5 } & $A_{2}$ & $\underline{13}$ & 5 & 18 \\
\hline & Total & 17 & 29 & 46 \\
\hline
\end{tabular}

Table 10. Preference and matching result in scenario II

\begin{tabular}{|c|c|c|c|c|c|}
\hline \multirow{2}{*}{ Preference } & \multicolumn{5}{|c|}{ Matching } \\
\cline { 2 - 6 } & & $B_{1}$ & $B_{2}$ & $B_{3}$ & Total \\
\cline { 2 - 6 } & $A_{2}$ & $\underline{36}$ & $\underline{25}$ & $\underline{28}$ & 56 \\
\hline & Total & 39 & 29 & 31 & 43 \\
\hline
\end{tabular}

In scenario II, Table 10 shows that the change of task sequence does not reduce the preference reversal rate. The underlined data in the matching task shows the result consistent with the equate-to-differentiate interpretation, and chi-square test ( $\left.p h i=-0.72, \chi^{2}(2)=62.67, p<0.01\right)$, explicitly explains the correctness of the principle of detective predominance in predicting choice behaviour. The introduction of walking-time attribute does not significantly affect the preference, which proves that individual choice is not a multi-dimensional integration process, but a non-compensatory equate-to-differentiate process.

Table 11. Preference and matching result in scenario III

\begin{tabular}{|c|c|c|c|c|c|}
\hline & Matching & \multicolumn{2}{|c|}{$\boldsymbol{B}_{1}$} & \multicolumn{2}{c|}{$\boldsymbol{B}_{2}$} \\
\cline { 2 - 6 } & Evaluation & $C_{1}$ & $C_{2}$ & $C_{1}$ & $C_{2}$ \\
\hline \multirow{2}{*}{ Preference } & $A_{1}$ & 9 & 0 & 78 & 0 \\
\cline { 2 - 6 } & $A_{2}$ & 0 & 49 & 0 & 13 \\
\hline
\end{tabular}

In scenario III, Table 11 shows that the difference of the best possible results is reduced, that "arriving 8 minutes in advance" and "arriving 10 minutes ahead of time" can be easily eliminated. So, most of the subjects choose the worst results as their basis. The underlined data indicates the result consistent with the equate-todifferentiate interpretation. $58 \%$ of the subjects evaluate to the Metro Line No.2 better and choose it at the same time. Participants subjectively believe that the consequences of being late are more severe, and matching task ( $p h i=-0.69, \chi^{2}(2)=71.84, p<0.01$ ) significantly explains the process of preference. In this scenario, the equate-to-differentiate interpretation can still significantly explain individual preferences, but the data shows that "preference" and "evaluation" are coincident, the socalled phenomenon "preference reversal" disappeared.

Table 12. Preference and matching data of scenario I to III

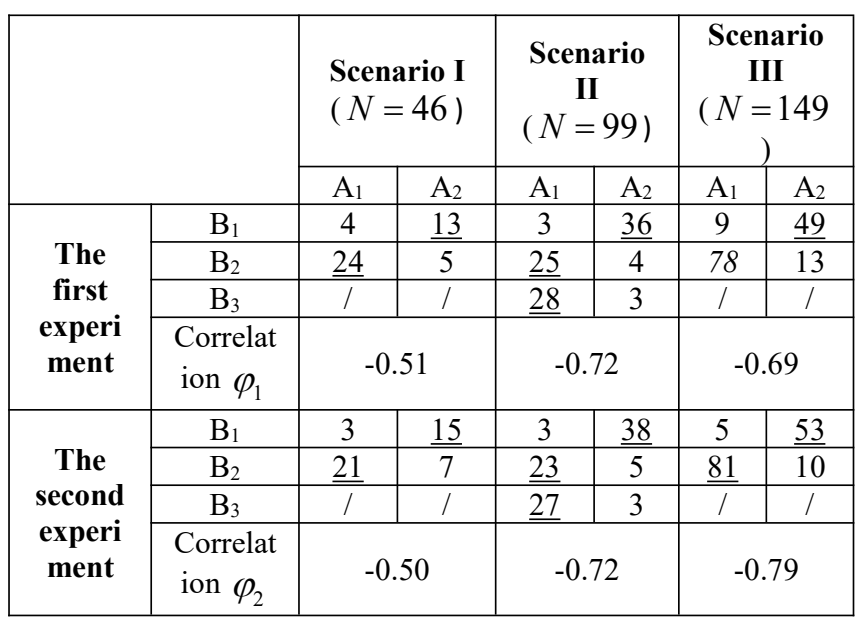

The result of second experiment is shown in Table 12 . The underlined data indicates the result which is consistent with the equate-to-differentiate interpretation. In both experiments of the three scenarios, "preference reversal" appear, the test results of matching options significantly explain the equate-to-differentiate process of choice and the equate-to-differentiate interpretation mechanism shows good consistency in the three groups of scenarios. It proves that the choice result can be explained and predicted through the judgment on the difference of travel mode attributes. But in the second experiment, some choices change.

Table 13. Test-retest data of choice consistency

\begin{tabular}{|c|c|c|c|c|c|c|c|}
\hline & \multicolumn{6}{|c|}{ The first experiment } \\
\hline & & \multicolumn{2}{|c|}{$\begin{array}{l}\text { Scenario I } \\
(N=46)\end{array}$} & \multicolumn{2}{|c|}{$\begin{array}{c}\text { Scenario II } \\
(N=99)\end{array}$} & \multicolumn{2}{|c|}{$\begin{array}{l}\text { Scenario III } \\
(N=149)\end{array}$} \\
\hline & & $\mathrm{A}_{1}$ & $\mathrm{~A}_{2}$ & $\mathrm{~A}_{1}$ & $\mathrm{~A}_{2}$ & $\mathrm{~A}_{1}$ & $\mathrm{~A}_{2}$ \\
\hline \multirow{2}{*}{$\begin{array}{c}\text { The } \\
\text { second } \\
\text { experi } \\
\text { ment }\end{array}$} & $\mathrm{A}_{1}$ & 16 & 8 & 31 & 22 & 52 & 34 \\
\hline & $\mathrm{A}_{2}$ & 12 & $\underline{10}$ & 15 & $\underline{21}$ & 35 & $\underline{38}$ \\
\hline \multicolumn{2}{|c|}{$\begin{array}{c}\text { Test-retest } \\
\text { reliability (r) }\end{array}$} & \multicolumn{2}{|c|}{$\begin{array}{c}0.12 \\
(\operatorname{sig}=0.40)\end{array}$} & \multicolumn{2}{|c|}{$\begin{array}{c}0.17 \\
(\operatorname{sig}=0.12)\end{array}$} & \multicolumn{2}{|c|}{$\begin{array}{c}0.17 \\
(\operatorname{sig}=0.11)\end{array}$} \\
\hline
\end{tabular}

As shown in Table 13, the underlined data indicates the number of subjects who make the same choice in the two experiments. In scenarios I-III, $43 \%, 37 \%$, and $46 \%$ of the subjects change their choice, but the test-retest reliability $(p<0.05)$ is not significant. It shows that the judgment of the attribute dimension is a dynamic process in the repeated either-or problem. 
Table 14. Test-retest data of consistency between choice and matching

\begin{tabular}{|c|c|c|c|c|c|c|c|}
\hline \multicolumn{2}{|c|}{} & \multicolumn{6}{|c|}{ Choice } \\
\cline { 2 - 8 } & \multicolumn{2}{|c|}{$\begin{array}{c}\text { Scenario I } \\
(N=46)\end{array}$} & \multicolumn{2}{c|}{$\begin{array}{c}\text { Scenario II } \\
(N=99)\end{array}$} & \multicolumn{2}{c|}{$\begin{array}{c}\text { Scenario III } \\
(N=149)\end{array}$} \\
\cline { 2 - 8 } & $\mathrm{D}$ & $\mathrm{S}$ & $\mathrm{D}$ & $\mathrm{S}$ & $\mathrm{D}$ & $\mathrm{S}$ \\
\hline \multirow{2}{*}{ Matching } & $\mathrm{D}$ & $\underline{10}$ & 7 & $\underline{40}$ & 11 & $\underline{47}$ & 8 \\
\cline { 2 - 8 } & $\mathrm{S}$ & 6 & $\underline{23}$ & 9 & $\underline{39}$ & 18 & $\underline{76}$ \\
\hline $\begin{array}{c}\text { Variation } \\
\text { interpretation } \\
\text { rate (R }\end{array}$ & \multicolumn{2}{|c|}{0.15} & \multicolumn{2}{|c|}{0.36} & \multicolumn{2}{|c}{0.42} \\
\hline
\end{tabular}

As shown in Table 14, S and D respectively represent the number of subjects with the same and inconsistent results between choice and matching in the two experiments. The underlined data indicates the number of subjects who change their choice and matching strategies simultaneously. The variability interpretation effect values are respectively $0.15,0.36$, and 0.42 in the three scenarios, and all of them significantly $(p<0.01)$ indicate that the choice variation of traffic mode can be explained by the change of the dimension judgment in the matching task under the equate-to-differentiate interpretation. And the summary data of the three groups of experiment is shown in table 15 .

Table 15. Summary data of statistical analysis

\begin{tabular}{|c|c|c|c|c|c|c|}
\hline Scenario & $\mathrm{N}$ & $\mathrm{D}$ & $\varphi_{1}$ & $\varphi_{2}$ & $\mathrm{r}$ & $\mathrm{R}^{2}$ \\
\hline I & 46 & 17 & - & - & 0.12 & $0.15^{* *}$ \\
& & & $0.51^{* *}$ & $0.50^{* *}$ & & \\
\hline II & 99 & 24 & $\begin{array}{c}- \\
-\end{array}$ & $\begin{array}{c}- \\
0.72^{* *}\end{array}$ & 0.17 & $0.36^{* *}$ \\
\hline III & 149 & 32 & $\begin{array}{c}- \\
0.69^{* *}\end{array}$ & $\begin{array}{c}- \\
0.79^{* *}\end{array}$ & 0.17 & $0.42^{* *}$ \\
\hline
\end{tabular}

\section{Comparative analysis}

In this paper, the decision field theory is used to simulate above scenarios, making the comparison from the side.

The decision field theory holds that the human decision process is the dynamic accumulation of preference in the activation of the human brain, and the simulation is made by constructing a diffusion process model. Specifically, suppose there are $n$ alternatives, $P(0)$ represents the initial preference strength and define $P(t)=\left\{p_{i}(t)\right\}(i=1,2, \cdots, n)$, where $p_{i}(t)$ is the preference strength of the alternative $i$ at time $t$. The evolution of the preference strength is represented by the following equation:

$$
P(t)=S \cdot P(t-h)+C \cdot M \cdot W(t)+E(t) \pi
$$

In the formula, $h$ is an arbitrarily small unit of time, $S$ is the feedback matrix, $M$ is the attribute matrix, $W$ is the attribute attention transfer matrix, $E(t) \pi$ is the random error term, $C$ is the comparison matrix, which is used to compare the weighted average of each alternative.

Both the decision field theory and the equate-todifferentiate theory recognize the randomness of selection. However, unlike the non-compensatory principle of equate-to-differentiate theory, the decision field theory considers that the formation of preferences is a process of random accumulation of each attribute's valence, and the difference of an attribute can be compensated by the accumulation of another one. Using the traffic attribute data of the initial survey, the simulation subjects are divided into two categories, teachers and students. According to the previous survey of attributes, the main diagonal elements of the feedback matrix are $s_{i i}=0.96$, and the input attention transfer probability matrix is as follows:

$$
w(t)_{1}=[0.55,0.22,0.23], \quad w(t)_{2}=[0.46,0.22,0.32] .
$$

Table 16 Attributes of two modes

\begin{tabular}{|c|c|c|c|}
\hline & $\begin{array}{c}\text { Ride time } \\
\text { (min) }\end{array}$ & $\begin{array}{c}\text { Walking time } \\
\text { (min) }\end{array}$ & Load factor \\
\hline $\begin{array}{c}\text { Metro Line } \\
\text { No.2 }\end{array}$ & 50 & 10 & $60 \%$ \\
\hline $\begin{array}{c}\text { Metro Line } \\
\text { No.4 }\end{array}$ & 40 & 15 & $80 \%$ \\
\hline
\end{tabular}

Assuming that the initial preferences are zero, the two groups are simulated 1000 times by MATLAB. The micro-evolutionary map of preference inversion in a repetitive decision-making of the teacher category is shown in Figure. 2 and Figure. 3.

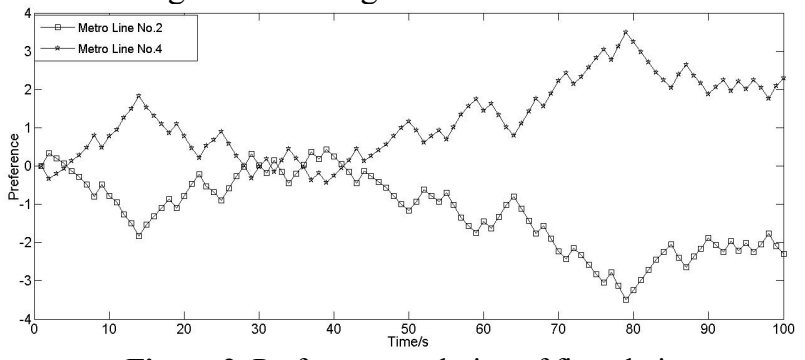

Figure 2. Preference evolution of first choice

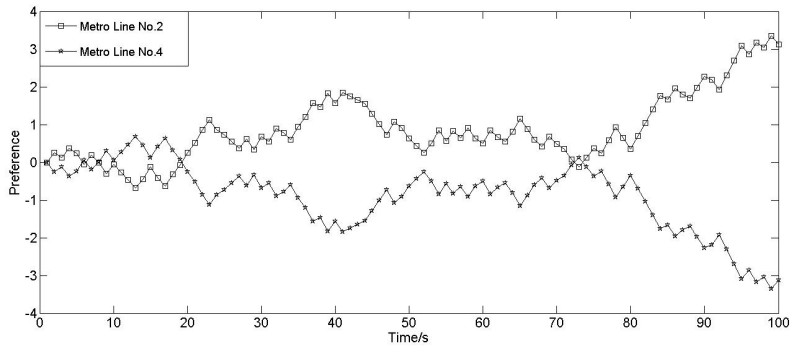

Figure 3. Preference evolution of choice reversal

The decision field theory shows the preference evolution results of two repeated decisions with the same input. For the first decision, Metro line No.4 is chosen, besides, Metro line No.2 is chosen for the second decision. The simulation results are shown in Table 17.

Table 17 The simulation results

\begin{tabular}{|c|c|c|c|c|}
\hline \multirow{2}{*}{ Choice } & \multicolumn{2}{|c|}{$\begin{array}{c}\text { Group one } \\
\left(w(t)_{1}=[0.55,0.22,0.23]\right)\end{array}$} & \multicolumn{2}{c|}{$\begin{array}{c}\text { Group two } \\
\left(w(t)_{2}=[0.46,0.22,0.32]\right)\end{array}$} \\
\cline { 2 - 5 } & $\begin{array}{c}\text { Selected } \\
\text { number }\end{array}$ & Percentage & $\begin{array}{c}\text { Selected } \\
\text { number }\end{array}$ & Percentage \\
\hline $\begin{array}{c}\text { Metro } \\
\text { Line } \\
\text { No.2 }\end{array}$ & 724 & $72.4 \%$ & 388 & $38.8 \%$ \\
\hline $\begin{array}{c}\text { Metro } \\
\text { Line } \\
\text { No.4 }\end{array}$ & 276 & $27.6 \%$ & 612 & $61.2 \%$ \\
\hline
\end{tabular}

Compared with the compensation-based decision field theory, the equate-to-differentiate theory can handle 
processing of fuzzy non-quantitative attribute indicators more flexibly, while the decision field theory requires strict quantitative data indicators.

The equate-to-differentiate theory attach importance to the statistics of decision-making results and cannot describe the micro-evolution process of preferences. However, the decision field theory can intuitively describe the evolution process of individual preferences.

The randomness in the decision field theory is reflected in the transfer process of attribute attention, and the formation of preference is the result of multi-attribute valence accumulating over time. Moreover, the result of inversion cannot be predicted. However, the equate-todifferentiate theory considers the decision-making process as the value judgment of the single attribute, and the inversion results can be predicted by matching experiments.

\section{Conclusion}

Some of the reversal phenomena cannot be well explained under the framework of the expected utility theory, and the reversals also cause some confusion and limitations in research and work. The experimental results show that the preference reversal and choice reversal phenomenon actually exist in the travel decision and the variation cannot be reasonably explained by cautious control and random error analysis. Traveler's decision of the transportation mode adopts completely different attitudes, the travel decision is an independent thinking process and the transmissibility principle is not significantly followed.

The analysis shows that, the phenomenon of "reversal" does not really stem from the decision inconformity, but the dimensional differences in the attributes of travel modes. The introduction of precise probability does not necessarily affect the traveler's decision metrics, and the attribute dimension difference is determined by the individual subjective values. If the same attribute dimension is followed in the decision, the reversals do not occur, and if the attribute dimension changes, the reversals do occur.

When faced with the decision that travel modes have the same expectation values, the detective superiority principle under the equate-to-differentiate interpretation can better explain and predict the preference reversal and choice reversal phenomenon. The Equate-to-differentiate Interpretation provides a new perspective for understanding and studying human risk decision-making behavior and provides an alternative explanation for the inconsistence of preferences and choices that shown in travel decision. When confronted with this inconsistence, there is no need to proceed from the "maximization" criterion, travelers can often consider the differences in different dimensions to change their strategies in a timely manner. This result in the behavior is seemingly abnormal but ecologically rational. This article has only carried on the exploration to the travel decision reversal phenomenon of either-or problem, and tried to carry on the theoretical explanation, and we also hope to introduce valuable remarks.

\section{References}

1. S. Lichtenstein, P. Slovic, Journal of Experimental Psychology, 89(1971)

2. D. M. Grether, C. R. Plott, American Economic Review, 69(1979)

3. R. J. Reilly, American Economic Review, 72(1982)

4. G. Loomes., R. Sugden., Economic Journal,. 92(1982)

5. C. A. Holt, American Economic Review, 76(1986)

6. E. Karni, Z. Safra, The Econometric Society, 55(1987)

7. U. Schmidt, J. D. Hey, Journal of Risk and Uncertainty, 29(2004)

8. BA. Mellers, LD. Ordóñez, H. M, Organizational Behavior \& Human Decision Processes, 52(1992),

9. M H. Birnbaum, G. Coffey, B.A. Mellers, et al. Journal of Experimental Psychology Human Perception \& Performance, 18(1992)

10. S. Li, Psychological Record, 56(2006)

11. S. Li, East China Normal University Press, (2015)

12. J. R. Busemeyer, J.T. Townsend, Psychological Review, 100(1993)

13. L. Shu, Acta Psychologica Sinica, 37(2005)

14. S. Li, International Journal of Creativity \& Problem Solving, 11(2001)

15. N. Zhang, X. Luo, Y.Deng, Journal of Transportation Systems Engineering and Information Technology, 18(2018) 